Gut, 1974, 15, 143-146

\title{
Properties of strains of Escherichia coli carried in different phases of ulcerative colitis
}

\author{
E. MARY COOKE ${ }^{1}$, SUSAN P. EWINS, J. HYWEL-JONES, AND \\ J. E. LENNARD-JONES 2
}

From the Department of Medical Microbiology, St Bartholomew's Hospital, London, and St. Mark's Hospital, City Road, London

SUMMARY Strains of $E$. coli from the faeces of patients with active ulcerative colitis and with colitis in remission were examined for haemolysin and necrotoxin production. Cultures from 63 patients with active colitis grew haemolytic $E$. coli in $23(37 \%)$ as compared with $24(21 \%)$ from 115 patients whose disease was in remission $(\mathrm{P}<0.05)$. The corresponding proportions for necrotoxin-producing strains were $22 \%$ and $12 \%$. Of 35 patients investigated both in relapse and remission of the colitis, 14 changed their carriage of haemolytic E. coli. Thirteen of these carried haemolytic organisms in relapse but not in remission, and one carried haemolytic organisms in remission but not in relapse $(\mathbf{P}<0.01)$.

Strains of $E$. coli were also examined from specimens of faeces obtained at weekly intervals for 28 weeks from 19 patients. The acquisition of haemolytic or necrotoxic $E$. coli strains tended to follow rather than precede the onset of the attack in the four patients who developed a relapse of the disease during this period. Among these 19 patients haemolytic and necrotoxic strains were found most commonly when blood was regularly present in the faeces. These facts suggest that conditions in the bowel during a relapse of colitis tend to favour the presence of haemolysin- and necrotoxinproducing organisms, rather than that these organisms cause the relapse.

Of 50 strains of $E$. coli from patients treated with sulphasalazine tested for sensitivity to sulphapyridine 49 were resistant. There was no clear relation between the activity of the colitis and the presence of any of the 27 serotypes of $E$. coli examined.

It has previously been shown in a small series of patients that the strains of Escherichia coli in the faeces of patients with ulcerative colitis differ from those of normal persons (Cooke, 1968). Two studies have been undertaken to extend this observation. In the first, the faecal coliform flora of patients with active colitis has been compared with that of patients whose disease was in remission; in the second, the time relations between a change in faecal flora and the activity of the disease were studied by examining the faeces of 19 patients at weekly intervals for six months. The opportunity has also been taken to assess the sensitivity to sulphapyridine of strains of $E$. coli from patients with colitis treated with sulphasalazine.

${ }^{1}$ Present address: Department of Microbiology, School of Medicine, The University of Leeds.

'Please send reprint requests to J. E. L-J., St. Mark's Hospital, London EC1V 2PS.

Received for publication 29 October 1973.

\section{Materials and Methods}

SOURCES OF SPECIMENS

In the first investigation, specimens were obtained by swabbing the colonic mucosa of patients with ulcerative colitis at the time of sigmoidoscopy. All specimens were obtained in the outpatient clinic except for those obtained from 11 patients on the day of admission to hospital. Faeces were also examined from 50 normal persons outside hospital.

The patients' condition was assessed by their symptoms and by the appearance of the colonic mucosa. Only patients who had symptoms of the disease and in whom the mucosa was bleeding or bled on contact were considered to have active colitis. The disorder was considered to be in remission if the colonic mucosa was non-haemorrhagic and the patient had no symptoms. Patients whose disease could not clearly be categorized in this way and 
patients with colitis in remission but in whom the disease had been active within the previous two months were not included in the series. Only one specimen from each patient in each period of activity or remission of the disease was examined.

In the second investigation, specimens of faeces were obtained at weekly intervals for 28 weeks from 19 patients with ulcerative colitis. With each specimen the patient sent a form on which his symptoms were noted (fig 1).

Fifty distinct strains of $E$. coli from 40 ulcerative colitis patients being treated with sulphasalazine, 50 strains from patients not being treated with sulphasalazine, and 50 strains from normal people were examined for sulphonamide sensitivity.

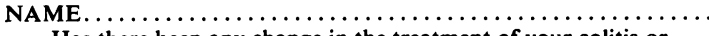
Has there been any change in the treatment of your colitis or have you had any treatment especially with antibiotics for any other illness during the last week?

\begin{tabular}{|c|c|}
\hline \multicolumn{2}{|c|}{ Bowels opened: -once a day, or less } \\
\hline & -1 to 3 times daily \\
\hline & -3 to 5 times daily \\
\hline & - more than 5 times daily \\
\hline The stool is: & -formed \\
\hline & - fluid \\
\hline The stool contains: & -no blood \\
\hline & $\begin{array}{l}\text {-blood in occasional small } \\
\text { amounts }\end{array}$ \\
\hline & -blood is regularly present \\
\hline The stool contains & -no mucus \\
\hline & -mucus is present \\
\hline During th & -completely well \\
\hline & $\begin{array}{l}\text {-fairly well } \\
\text {-unwell }\end{array}$ \\
\hline
\end{tabular}

Please tick where applicable

$\cdots \cdots$

$\ldots \ldots$

$\ldots \ldots$

$\ldots \ldots$

$\cdots \cdots$

$\cdots \cdots$

$\cdots \cdots$

$\ldots \ldots$

$\ldots \ldots$

$\cdots \cdots$

$\ldots \ldots$

$\ldots \ldots$

$\ldots \ldots$

$\cdots \cdots$

$\ldots \ldots$

Fig 1 Form completed each week by ulcerative colitis patients in the second investigation

EXAMINATION OF SPECIMENS

The swabs and faeces were plated on to washed horse blood agar and MacConkey agar medium. Ten colonies of each colonial type of coliform organism were examined from each specimen. Identification and serotyping using 27 antisera were carried out as previously described (Cooke, Ewins, and Shooter, 1969).Haemolysin production in liquid and solid media and necrotoxin production on intradermal injection into rabbits were detected as previously (Cooke, 1968). Sensitivity of a strain of $E$. coli to sulphapyridine was tested by placing a solution containing $500 \mu \mathrm{g}$ of the drug in a hole in a MacConkey plate which had been inoculated with a suspension of the organism in peptone water. Control observations were made using strains of $E$. coli of known sensitivity to the drug.

\section{Results}

PROPORTIONS OF HAEMOLYTIC AND

NECROTOXIC STRAINS OF E. COLI

ISOLATED FROM PATIENTS WITH ACTIVE

DISEASE OR COLITIS IN REMISSION

The relationship between the clinical state of 178 different patients and haemolysin and necrotoxin production by their colonic $E$. coli is shown in table I. Twenty-three of 63 specimens from patients with active disease contained haemolytic $E$. coli compared with 24 of 115 from patients with colitis in remission $(P<0.05)$. Similarly, more specimens from patients in relapse contained necrotoxin-producing strains (14 of 63) than did those from patients in remission (14 of 115). Necrotoxin production tended to occur within a strain which also produced haemolysin.

\begin{tabular}{llll}
\hline $\begin{array}{l}\text { Source of } \\
\text { Specimens }\end{array}$ & $\begin{array}{l}\text { Total } \\
\text { Specimens } \\
\text { Examined }\end{array}$ & $\begin{array}{l}\text { Specimens } \\
\text { Yielding } \\
\text { Haemolytic }\end{array}$ & $\begin{array}{l}\text { Specimens } \\
\text { Yielding } \\
\text { Necrotoxic } \\
\text { E. coli }\end{array}$ \\
\hline Active colitis & 63 & $23^{1}$ & 14 \\
Colitis in remission & 115 & $24^{1}$ & 14 \\
Normal subjects & 50 & 10 & 7 \\
\hline
\end{tabular}

Table I Carriage of haemolysin- and necrotoxinproducing strains of Escherichia coli in the faeces of 50 normal subjects, 63 patients with active colitis, and 115 patients with colitis in remission

${ }^{1} x^{2}=5 \cdot 12, \mathrm{n}=1, \mathrm{P}=<0.05$.

The age and sex of the patients were not associated with any marked differences in the carriage of haemolysin-producing organisms.

During activity of the disease, treatment of the patient with sulphasalazine did not affect the proportion of haemolytic organisms cultured. In remission a slight reduction was observed in the proportion of haemolytic organisms cultured from patients being treated with sulphasalazine $(12 / 75)$ as compared with patients not receiving the drug $(12 / 40)$ but this difference may have occurred by chance.

CHANGES IN THE E. COLI FLORA OF PATIENTS SEEN BOTH IN RELAPSE AND REMISSION

Thirty-five patients were seen from whom specimens were obtained both when the colitis was active and in remission (table II). Of these, 21 showed no change in the carriage of haemolytic $E$. coli (seven carried haemolytic $E$. coli in both relapse and remission). Of the remainder who changed their carriage of haemolytic $E$. coli, 13 carried haemolytic organisms in relapse but not in remission and one carried haemolytic organisms in remission but not in relapse $(\mathrm{P}<0.01)$. 


\begin{tabular}{|c|c|c|c|c|}
\hline \multicolumn{4}{|c|}{ 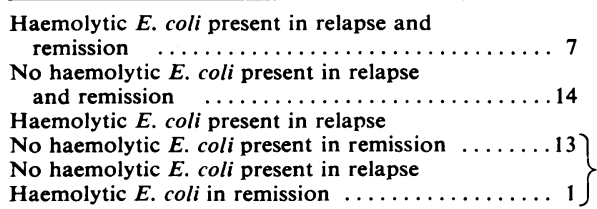 } & $\begin{array}{l}P<0.01 \\
(\text { Sign test })\end{array}$ \\
\hline $\begin{array}{l}\text { Relapse } \\
\text { Haemolytic } \\
\text { E. coli } \\
\text { Present } \\
20\end{array}$ & $\begin{array}{l}\text { Haemolytic } \\
\text { E. coli } \\
\text { Absent } \\
15\end{array}$ & $\begin{array}{l}\text { Remission } \\
\text { Haemolytic } \\
\text { E. coli } \\
\text { Present } \\
8\end{array}$ & & $\begin{array}{l}\text { nolytic } \\
\text { li } \\
\text { nt }\end{array}$ \\
\hline
\end{tabular}

Table II Carriage of haemolytic Escherichia coli by 35 patients studied both in relapse and remission of ulcerative colitis

Eight patients were seen in whom there were two relapses with a clear period of remission between the attacks of the disease. In five of these patients both relapses were associated with the presence of a haemolysin- or necrotoxin-producing strain which was not isolated during the intervening period of remission. From two of the patients the same serotype was isolated during both relapses but not during the period of remission.

INVESTIGATION INTO THE TIME RELATIONS BETWEEN A CHANGE IN THE STRAIN OF E. COLI AND RELAPSE OF THE DISEASE During the six months of the investigation, many of the 19 patients studied weekly suffered from minor symptoms of colitis which changed little. A haemolysin- or necrotoxin-producing strain was isolated on one or more occasions from 17 of the 19 patients. Only four of the patients suffered from a clear-cut relapse of colitis. These four patients carried haemolysin- or necrotoxin-producing strains only during the acute episode. The acquisition of strains during the episode was as follows: (1) One patient acquired a haemolytic strain after five weeks which persisted for seven weeks. (2) One patient acquired a necrotoxin-producing strain after three weeks which persisted for three weeks. (3) One patient acquired a haemolysin- and necrotoxin-producing strain after five weeks. A haemolysin-producing strain persisted for nine weeks and a necrotoxin-producing strain for 14 weeks. (4) One patient acquired a haemolytic strain after eight weeks which persisted for six weeks.

\section{CORRELATION BETWEEN THE PRESENCE OF} BLOOD IN THE FAECES AND THE PRESENCE OF A HAEMOLYTIC OR NECROTOXIC STRAIN OF E. COLI

In the 19 patients studied weekly for 28 weeks it was possible to correlate the presence or absence of a haemolytic or necrotoxic strain of $E$. coli in the stools with the patients' statements that hlood was present regularly or that no blood was seen in the stools during the previous week. Specimens from patients who reported that blood was present in occasional small amounts were excluded from this analysis. The results shown in table III indicate that both haemolysin- and necrotoxin-producing $E$. coli were found more commonly in the stools of patients who regularly observed blood in the stools than when visible blood was absent.

\begin{tabular}{|c|c|c|c|}
\hline $\begin{array}{l}\text { Symptoms during } \\
\text { Previous Week }\end{array}$ & $\begin{array}{l}\text { No. of } \\
\text { Specimens }\end{array}$ & $\begin{array}{l}\text { Haemolysin- } \\
\text { producing } \\
\text { E. coli } \\
\text { Present }\end{array}$ & $\begin{array}{l}\text { Nectrotoxin- } \\
\text { producing } \\
\text { E. coli } \\
\text { Present }\end{array}$ \\
\hline $\begin{array}{l}\text { Blood regularly } \\
\text { present } \\
\text { No blood present }\end{array}$ & $\begin{array}{r}38 \\
238\end{array}$ & $\begin{array}{l}17 \\
(45 \%) \\
45 \\
(19 \%)\end{array}$ & $\begin{array}{l}12 \\
(32 \%) \\
43 \\
(18 \%)\end{array}$ \\
\hline
\end{tabular}

Table III Comparison between the presence of haemolysin- and necrotoxin-producing Escherichia coli in specimens of faeces when blood was regularly reported and when no blood was reported

CORRELATION OF SULPHASALAZINE TREATMENT WITH SENSITIVITY OF E. COLI STRAINS TO SULPHAPYRIDINE

Of the 50 strains of $E$. coli from patients on sulphasalazine examined for their sensitivity to sulphapyridine, 49 were resistant. Twenty-seven of 50 strains from patients not on sulphasalazine were resistant to sulphapyridine and 10 of 50 strains from normal people. We could demonstrate no association between sulphonamide resistance and haemolysin production by these organisms.

OTHER BACTERIOLOGICAL OBSERVATIONS There was no marked correlation of any one serotype of $E$. coli with the clinical state of the patients. Of the strains from patients with active colitis, $12 \%$ were serotype 02 whereas $8 \%$ of strains from patients with disease in remission and from normal people belonged to this group. The strains which were non-typeable with the antisera used made up $31 \%$ of the strains from patients with active disease, $33 \%$ of those from patients in remission, and $45 \%$ of those from normal people. Certain serotypes of $E$. coli more commonly produce a haemolysin and necrotoxin than do others. In this series these were 01,04 , 06,018 , and 025 . Of the 403 haemolysin-producing strains examined, $209(52 \%)$ produced a haemolysin detected only in a liquid medium and $30(7 \%)$ produced a haemolysin detected only on solid media. In the remainder, the haemolysin was detected in both media.

\section{Discussion}

The factors affecting the strains of $E$. coli carried in 
the bowel are poorly understood. Some workers have found the coliform population of the bowel to be relatively stable (Sears, Brownlee, and Uchiyama, 1950) but other work has indicated that under contions in which $E$. coli are ingested in large numbers in food the faecal coliform flora may change (Cooke, et al, 1969; Cooke, Shooter, Kumar, Rousseau, and Foulkes, 1970). The factors governing the fate of ingested coliforms are not known. Some strains appear to establish themselves in the bowel more readily than others and there are also differences in the fate of a single strain in different subjects so that both the nature of the organism and the characteristics of the host are involved (Cooke, Hettiaratchy, and Buck, 1972). Gorbach, Nahas, Plaut, Weinstein, Patterson, and Levitan (1968) demonstrated an increased number of coliforms in patients with severe colitis but the strains and properties of these coliforms were not considered.

In the present study the properties of the coliforms cultured from the faeces of patients with colitis tended to differ according to the activity of the disease. Patients were more likely to carry haemolysin- and necrotoxin-producing strains during an attack of colitis than were patients whose disease was in remission. Among the 35 patients from whom cultures were obtained both in relapse and remission, there was a tendency for the coliforms to change from a non-haemolytic to a haemolytic strain.

Few tests of pathogenicity of $E$. coli are at present known. Haemolysin- and necrotoxin-producing strains of $E$. coli have been considered to be particularly pathogenic in such situations as urinary tract infections and peritonitis (Vahlne, 1945; Sjöstedt, 1946; Kaufmann, 1948) and they are also associated with some diarrhoeal disease of animals (Sojka, Erskine, and Lloyd, 1957). It is possible that in a patient with quiescent ulcerative colitis, multiplication of these organisms in the colon could initiate a relapse of the disease. Alternatively, conditions in the bowel during a relapse of colitis may favour the multiplication of haemolytic $E$. coli so that organisms which are normally present in such small numbers as to be undetectable multiply and become the predominant flora.

The evidence from the prospective study suggests that a change in the flora from a non-haemolytic to a haemolytic type tends to follow rather than precede an attack of colitis. The data suggests that haemolytic organisms are associated with the presence of blood in the stools. Whether the presence of haemolysis or necrotoxin-producing organisms in the colon affects the duration or severity of the attack is not known.

The effect of sulphasalazine in ulcerative colitis is of interest because this drug is of proven benefit in acute disease and has also been shown to reduce the relapse rate (Misiewicz, Lennard-Jones, Connell, Baron, and Avery Jones, 1965). Of the 50 strains of $E$. coli from patients being treated with sulphasalazine which were examined for sulphonamide sensitivity, 49 were resistant. In 150 strains of $E$. coli examined, no relationship was found between sulphonamide resistance and haemolysin production. Our results suggest that the beneficial effect of sulphasalazine cannot be ascribed to an effect on the $E$. coli flora of the bowel.

Further study of the aerobic and anaerobic bacterial flora of the colon might indicate factors causing a relapse of colitis and determining its severity, The strains of $E$. coli isolated in this work were typed using 270 antisera and no marked differences were demonstrated between the serotypes of $E$. coli present in normal people and in the patients with colitis. At the present time, 1500 groups and their associated $\mathrm{K}$ antigens and 49 flagellar antigens have been identified, and it is possible that more extensive serotyping would demonstrate differences not detected by the limited number of antisera used in this study. More important, however, would appear to be studies of the pathogenicity of the organisms by investigation of other types ot toxin, of the ability of the organisms to invade the mucosa, and perhaps the capacity of the organisms to induce an immunological reaction by the host.

We thank Dr J. J. Misiewicz and Dr J. A. Parrish for their help in this investigation.

\section{References}

Cooke, E. M. (1968). Properties of strains of Escherichia coli isolated from the faeces of patients with ulcerative colitis, patients with acute diarrhoea and normal persons. J. Path. Bact., 95, 101-113.

Cooke, E. M., Ewins, S. P., and Shooter, R. A. (1969). Changing faecal population of Escherichia coli in hospital medical patients. Brit. med. J., 4, 593-595.

Cooke, E. M., Shooter, R. A., Kumar, P. J., Rousseau, S. A., and Foulkes, A. L. (1970). Hospital food as a possible source of Escherichia coli in patients. Lancet, 1, 436-437.

Cooke, E. M., Hettiaratchy, I. G. T., and Buck, A. C. (1972). Fate of Escherichia coli. in normal persons. J. Med. Microbiol., 5, 361369.

Gorbach, S. L., Nahas, L., Plaut, A. G., Weinstein, L., Patterson, J. F., and Levitan, R. (1968). Studies of intestinal microflora. Gastroenterology, 54, 575-587.

Kauffmann, F. (1948). Die Coli-Theorie der Appendicitis. Schweiz. Z. Path., 11, 553-569.

Misiewicz, J. J., Lennard-Jones, J. E., Connell, A. M., Baron, J. H., and Jones, F. A. (1965). Controlled trial of sulphasalazine in maintenance therapy for ulcerative colitis. Lancet, 1, 185-188.

Sears, H. J., Brownlee, I., and Uchiyama, J. K. (1950). Persistence of individual strains of Escherichia coli in the intestinal tract of man. J. Bact., 59, 293-301.

Sjöstedt, S. (1946). Pathogenicity of certain serological types of $B$. coli. Acta path. microbiol. scand., Suppl. 63.

Sojka, W. G., Erskine, R. G., and Lloyd, M. K. (1957). Haemolytic Escherichia coli and 'oedema disease' of pigs. Vet. Rec., 69, 293301.

Vahlne, G. (1945). Serological typing of the colon bacteria. Acta path. microbiol. scand., Suppl. 62. 